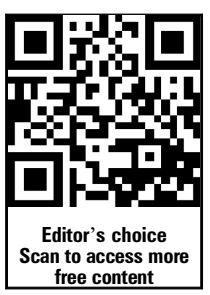

- Additional material is published online only. To view please visit the journal online (http://dx.doi.org/10.1136/ oemed-2014-102178).

${ }^{1}$ Office of Environmental Health Hazard Assessment, California Environmental Protection Agency, Oakland, California, USA

${ }^{2}$ Office of Environmental Health Hazard Assessment, California Environmental

Protection Agency, Sacramento, California, USA

${ }^{3}$ Occupational Medicine, Kaiser Permanente, Oakland,

California, USA

\section{Correspondence to}

Dr Craig Steinmaus, Office of Environmental Health Hazard Assessment, 1515 Clay Street, 16th Floor, Oakland,

CA 94612 USA

craigs@berkeley.edu

Received 13 March 2014 Revised 3 September 2014 Accepted 9 September 2014 Published Online First 17 September 2014

\title{
Chromium VI and stomach cancer: a meta-analysis of the current epidemiological evidence
}

\author{
Roberta Welling, ${ }_{1}$ James J Beaumont, ${ }^{2}$ Scott J Petersen, ${ }^{3}$ George V Alexeeff, ${ }^{2}$ \\ Craig Steinmaus $^{1}$
}

\begin{abstract}
Objectives Chromium VI (hexavalent chromium, $\operatorname{Cr}(\mathrm{VI})$ )

is an established cause of lung cancer, but its association with gastrointestinal cancer is less clear. The goal of this study was to examine whether the current human epidemiological research on occupationally inhaled $\mathrm{Cr}(\mathrm{VI})$ supports the hypothesis that $\mathrm{Cr}(\mathrm{VI})$ is associated with human stomach cancer.

Methods Following a thorough literature search and review of individual studies, we used meta-analysis to summarise the current epidemiological literature on inhaled $\mathrm{Cr}(\mathrm{VI})$ and stomach cancer, explore major sources of heterogeneity, and assess other elements of causal inference.
\end{abstract}

Results We identified 56 cohort and case-control studies and 74 individual relative risk (RR) estimates on stomach cancer and $\mathrm{Cr}(\mathrm{VI})$ exposure or work in an occupation associated with high $\mathrm{Cr}(\mathrm{VI})$ exposure including chromium production, chrome plating, leather work and work with Portland cement. The summary RR for all studies combined was $1.27(95 \% \mathrm{Cl} 1.18$ to 1.38). In analyses limited to only those studies identifying increased risks of lung cancer, the summary $\mathrm{RR}$ for stomach cancer was higher $(\mathrm{RR}=1.41,95 \% \mathrm{Cl}$ 1.18 to 1.69 ).

Conclusions Overall, these results suggest that $\mathrm{Cr}(\mathrm{VI})$ is a stomach carcinogen in humans, which is consistent with the tumour results reported in rodent studies.

\section{INTRODUCTION}

Inhalation of hexavalent chromium $(\mathrm{Cr}(\mathrm{VI}))$ has occurred in a number of industries, including leather tanning, chrome plating, cement work and stainless steel welding and manufacturing. Numerous studies have identified associations between lung cancer and inhaled $\mathrm{Cr}(\mathrm{VI})$ in occupational settings, and the International Agency for Research on Cancer has classified $\mathrm{Cr}(\mathrm{VI})$ as a group I carcinogen, based primarily on studies of chromate production, chromate pigment production and chromium electroplating involving high exposures. ${ }^{1}$ Given that the lung is directly exposed to inhaled $\mathrm{Cr}(\mathrm{VI})$, it is not surprising that this organ is a target site. However, several studies suggest that $\mathrm{Cr}(\mathrm{VI})$ may also have carcinogenic effects in other internal organs, including the gastrointestinal tract.

The issue of whether $\mathrm{Cr}(\mathrm{VI})$ causes gastrointestinal cancer has implications not only in exposed workers, but also in people who ingest $\mathrm{Cr}(\mathrm{VI})$ in drinking water. In a recent survey of 35 large US cities, $\mathrm{Cr}(\mathrm{VI})$ was detected in $89 \%$ of the water systems tested. ${ }^{2}$ All levels were below the US Environmental Protection Agency's (US EPA)
What this paper adds

Few studies have investigated the possible association between exposure to hexavalent chromium $(\mathrm{Cr}(\mathrm{VI}))$ and cancers other than respiratory cancers.

- This meta-analysis includes many more results than previous meta-analyses of $\mathrm{Cr}(\mathrm{VI})$ exposure and stomach cancer.

- Studies that were positive for lung cancer, which may indicate higher exposures, produced a higher summary relative risk for stomach cancer than the full meta-analysis.

- Possible mechanisms by which $\mathrm{Cr}(\mathrm{VI})$ might induce carcinogenesis are biologically plausible.

regulatory standard for chromium of $100 \mu \mathrm{g} / \mathrm{L}$. However, this standard is based on a health risk assessment over 20 years old and is for total chromium (Cr(VI) and $\mathrm{Cr}(\mathrm{III})$ combined), not the more toxic $\mathrm{Cr}(\mathrm{VI})$. Based at least partially on its possible carcinogenicity in the gastrointestinal tract, US EPA and others are in the process of evaluating the need for a new $\mathrm{Cr}(\mathrm{VI})$ drinking water standard. To date, however, the evidence linking $\mathrm{Cr}(\mathrm{VI})$ to gastrointestinal cancer comes primarily from animal studies and questions have been raised about their relevance to humans. Our goal was to evaluate whether evidence from human studies supports the hypothesis that $\mathrm{Cr}(\mathrm{VI})$ is a cause of gastrointestinal cancer.

We performed a meta-analysis of human studies of $\mathrm{Cr}(\mathrm{VI})$ and stomach cancer in order to provide a review of the current literature, evaluate causal inference, and assess potential sources of bias and heterogeneity. Although we examined several types of gastrointestinal cancer, including oesophageal, small intestine and colon cancer, initial analyses showed that the greatest number of studies and clearest associations were seen for stomach cancer; thus, stomach cancer is the focus of this meta-analysis.

\section{METHODS}

Databases including Medline and EMBASE were searched by two authors independently (RW and CS) for all epidemiological studies on $\mathrm{Cr}(\mathrm{VI})$ and stomach cancer (ICD-9 code 151). Searches included combinations of the keywords or phrases: stomach, gastric, gastrointestinal, cancer, chromium, leather, tanning, stainless steel, cement,
Beaumont JJ, Petersen $\mathrm{SJ}$ et al. Occup Environ Med 2015;72:151-159. 
concrete, welding and metal plating. We also searched bibliographies of all publications included in the meta-analysis and all relevant review articles.

The meta-analysis included studies that provided relative risk (RR) estimates either specifically for $\mathrm{Cr}(\mathrm{VI})$ exposure or for workers in occupations known to be associated with $\mathrm{Cr}(\mathrm{VI})$ exposure, including chromate or chromium production and plating; leather work and tanning; Portland cement work; and stainless steel production, welding, polishing and grinding. Very few human studies have examined $\mathrm{Cr}(\mathrm{VI})$ in drinking water. Owing to this, and in order to maintain consistency by route of exposure, we excluded drinking water studies from the meta-analysis and review them in the discussion.

Only data published in peer-reviewed scientific journals were used, and government or industry reports were excluded. Studies of general foundry work and construction were also excluded because exposure is most likely low in many of these workers. Studies of asbestos cement workers and studies of shoe manufacturing, welding and metal plating that did not specifically evaluate chromium, stainless steel or leather workers were also excluded. Studies that reported no cases of stomach cancer were also excluded because of the inability to calculate a variance estimate, although this exclusion was evaluated in sensitivity analyses. In a few instances, a single paper reported separate RR estimates for men and women, or separate RR estimates for workers in different job categories or at different worksites. In these instances, we included all relative risks meeting our inclusion criteria when no clear overlap was present. We used Byar's approximation to estimate CIs in cohort studies in which they were not provided. ${ }^{3}$ Each study was reviewed, and RR estimates and other information were abstracted independently by two authors (RW and CS).

Some studies gave RR estimates for several different metrics of $\mathrm{Cr}(\mathrm{VI})$ exposure, such as average exposure, peak exposure or exposure duration. In observational epidemiology, it is uncommon for all, or even most, studies to report findings using the same exposure metric. As a consequence, meta-analyses frequently involve combining data on different metrics. This meta-analysis is no different. When studies included RR estimates for different exposure metrics, we selected a single one in the following order: average exposure intensity, cumulative exposure and exposure duration. We chose this order a priori since analyses of other carcinogens have shown that exposure intensity may have a greater impact on cancer risks than exposure duration. ${ }^{4} 5$ Several studies also reported relative risks for different levels of exposure (eg, high, medium, low). Since our goal was to evaluate whether an association exists, rather than defining exact dose-response relationships or exact low exposure risks, we selected the RR for the highest exposure category. If a true association exists, higher exposures will usually be associated with higher relative risks, and higher relative risks, all else being equal, have greater statistical power and are less likely to be due to bias or confounding than relative risks near $1.0 .^{6} 7$ The selected studies reported incidence rate ratios, ORs, standardised incidence ratios (SIRs) standardised mortality ratios (SMRs) or proportionate mortality ratios (PMRs). Some studies reported RR estimates adjusted for variables such as smoking, and these were used when available. For studies reporting data on incidence and mortality, incidence data were selected. Some studies reported results for different latency periods (ie, the time from first exposure to cancer diagnosis or death). Since many environmental agents can take decades to lead to detectable cancers, we chose the result for the longest latency, up to a maximum of $30+$ years. For many cohort studies, publication of initial results was followed by updates, usually extending the period of follow-up. In these, we used the most recent publication giving the selected exposure metric or the largest number of cases. In a few publications of cement and leather work, $\mathrm{Cr}$ (VI) exposure was not specifically mentioned by the authors. These were included if the work processes described were those known to involve $\mathrm{Cr}(\mathrm{VI})$ exposure (eg, tanning or Portland cement). Inclusion and exclusion criteria are summarised in box 1 .

In order to explore heterogeneity, we performed subgroup analyses on specific occupations, study design, incidence versus mortality, gender and country. Since it is possible that $\mathrm{Cr}(\mathrm{VI})$

Box 1 Criteria for inclusion and exclusion of studies in the meta-analysis of $\mathrm{Cr}(\mathrm{VI})$ and stomach cancer

Inclusion criteria

- Epidemiological studies of stomach cancer and $\mathrm{Cr}(\mathrm{VI})$ exposure or work in an occupation known to be associated with $\mathrm{Cr}(\mathrm{VI})$ exposure including chromate or chromium production and plating; leather work and tanning; Portland cement work; and stainless steel production, welding, polishing and grinding

- Studies providing a relative risk estimate (including incidence rate ratios, ORs, standardised incidence ratios, standardised mortality ratios or proportionate mortality ratios) and the relative risk estimate's variance (or the data to calculate or estimate it)

- Published in peer-reviewed scientific journals

- If relative risk estimates are provided for different exposure metrics in a given study population, one metric was selected in the following order: average intensity, cumulative exposure, exposure duration

- If relative risk estimates are provided for different exposure levels in a given study population, the relative risk estimate for the highest level was selected

- Relative risk estimates adjusted for age, sex, smoking, diet and/or socioeconomic status were selected over unadjusted results

- If relative risk estimates for both stomach cancer mortality and incidence are reported in a given study population, the result for incidence was selected

- If relative risk estimates for different latency periods are reported in a given study population, the result for the longest latency period up to a period of $30+$ years was selected

- For studies or relative risk estimates with overlapping populations, the most recent relative risk estimate with the selected exposure metric (eg, exposure intensity vs cumulative exposure; high vs low exposure level) or largest number of cases was selected

Exclusion criteria

- Unpublished data including government or industry reports

- Occupations such as painting, general foundry work, construction and shoe (non-leather) manufacturing

- Welding or metal plating studies that did not evaluate stainless steel or chromium work

- Studies involving work with asbestos cement

- Studies of all gastrointestinal cancers combined

- Studies of $\mathrm{Cr}(\mathrm{VI})$ in drinking water

- Studies reporting no cases of stomach cancer 
exposures were too low in some studies to identify a true association, we conducted separate analyses of $\mathrm{Cr}(\mathrm{VI})$ and stomach cancer that included only studies in which elevated relative risks were identified for lung cancer, a well-established effect of high $\mathrm{Cr}(\mathrm{VI})$ exposure. In this analysis, since statistical significance is highly dependent on sample size (not just the presence of a true effect), we included all studies in which the RR of lung cancer was $\geq 1.5$ regardless of statistical significance. Several subgroup and other analyses were done to evaluate potential confounding (eg, from smoking) and to compare our meta-analysis to other recent meta-analyses on this topic.

We calculated summary RR estimates using the fixed and random effects models. ${ }^{8} 9$ We assessed heterogeneity among studies using the general variance-based method as described by Petitti. ${ }^{10}$ Statistical heterogeneity was defined as present if the $p$ value of the $\chi^{2}$ test statistic was below 0.05 . Some authors have suggested that because the random effects model incorporates between-study heterogeneity, it is more conservative than the fixed effects model. ${ }^{10}$ However, a potential problem with the random effects model is that, unlike the fixed effects model, study weighting is not directly proportional to study precision. As a consequence, the random effects model gives relatively greater weight to smaller, less precise studies than the fixed effects model. This can sometimes lead to summary results that are less conservative than those produced using the fixed effects model. ${ }^{11}$ To avoid this problem, we used the method presented by Shore et $a l^{12}$ for our main results. In this method, the summary RR estimate is calculated by directly weighting individual studies by their precision, and between-study variability is only incorporated into calculations of variance (ie, the 95\% CI). We assessed publication bias using funnel plots and Egger's and Begg's tests. ${ }^{13} 14$ The funnel plot is a graphical presentation of each study's effect size versus an estimate of its precision. This plot can be asymmetric if smaller studies with results that are null or in the unexpected direction are not published. In Egger's test, asymmetry in the funnel plot is formally tested by performing a simple linear regression of the effect size divided by its SE on the inverse of the SE. In Begg's test, Kendall's rank order test is used to evaluate whether there is a correlation between the studies' effect sizes and their SEs. All calculations were performed using Microsoft Excel 2010 or STATA V.12 (College Station, Texas, USA) and all $\mathrm{p}$ values are two sided.

\section{RESULTS}

In total, $74 \mathrm{RR}$ estimates, from 56 separate publications, met our inclusion criteria and were included in the meta-analysis (see online supplementalary table S1). Overall, 63 results $(85 \%)$ were selected from cohort studies and 11 (15\%) from casecontrol studies, and the meta-analysis involved studies that included 1399 cases of stomach cancer. Eighteen studies (24\%) involved chromium production or plating, 23 (31\%) involved cement workers, 17 (23\%) involved leather work including tanning, four $(5 \%)$ involved $\mathrm{Cr}(\mathrm{VI})$ or stainless steel welding, and $12(16 \%)$ involved other occupations such as ferrochromium or other stainless steel work. Studies excluded from the meta-analysis and the reasons for their exclusion are shown in online supplementalary table S2.

The summary relative risk for all studies combined was 1.27 (95\% CI 1.18 to $1.38 ; \mathrm{p}<0.001$; table 1 ). A forest plot summarising the results and weights applied to each study is shown in figure 1 . Seventy per cent of the individual RR estimates in the overall analysis were $>1.0$. No single RR estimate received more than $14 \%$ of the total weight showing that no single study dominated the assigned weights. Summary relative risks were elevated for cement $(1.29 ; 95 \%$ CI 1.17 to 1.42$)$ and leather work $(1.46$; $95 \%$ CI 1.23 to 1.72$)$ but not for welding (1.06; $95 \%$ CI 0.72 to 1.56$)$. For studies of $\mathrm{Cr}(\mathrm{VI})$ production and plating, the summary RR was above $1.0(1.25$; 95\% CI 0.97 to $1.60)$, but the $95 \%$ CI included 1.0. Summary relative risks were higher in case-control $(1.55 ; 95 \%$ CI 1.16 to 2.07$)$ than in cohort studies $(1.26$; 95\% CI 1.16 to 1.37$)$, males $(1.30$; $95 \%$ CI 1.20 to 1.41$)$ than in females $(1.08$; $95 \%$ CI 0.65 to $1.81)$, and in studies of mortality $(1.39 ; 95 \%$ CI 1.24 to 1.57$)$ than in studies of incidence $(1.17 ; 95 \%$ CI 1.07 to 1.29$)$, but differences were only statistically significant when studies of incidence and mortality were compared $(p=0.02)$. In the studies that identified $\mathrm{Cr}(\mathrm{VI})$-associated lung cancer relative risks $\geq 1.5$ (the proxy measure for probable higher exposure), the stomach cancer summary relative risk was 1.41 (95\% CI 1.18 to 1.69; $\mathrm{p}<0.001$ ) in all studies (figure 2) and 1.36 (95\% CI 1.01 to $1.81 ; \mathrm{p}=0.04)$ in $\mathrm{Cr}(\mathrm{VI})$ production and plating studies. The variables adjusted or stratified for in each study are shown in online supplementalary table S1. Only nine studies adjusted for some indicator of smoking, diet or socioeconomic status (SES), and the RR for these studies was 1.31 (1.01 to 1.69). Results in almost all analyses were similar regardless of whether the random effects model or the fixed effects model with the correction for between-study variability was used. For example, in the meta-analysis of all studies combined, the results using these two models were 1.28 (95\% CI 1.16 to 1.41$)$ and 1.27 (95\% CI 1.18 to 1.38$)$, respectively.

We saw no evidence of asymmetry in the funnel plot of all studies combined (figure 3), or in the funnel plots of each subgroup analysis (not shown). Egger's and Begg's tests also showed no consistent evidence of publication bias. For example, in the all studies combined analysis, the bias coefficient for Egger's test was $0.16(p=0.55)$. In the analysis of all studies with lung cancer relative risks $\geq 1.5$, the Egger's bias coefficient was $0.22(p=0.64)$.

\section{DISCUSSION}

The overall summary relative risk of 1.27 (95\% CI 1.18 to 1.38, $\mathrm{p}<0.001)$ provides evidence that $\mathrm{Cr}(\mathrm{VI})$ inhalation increases the risk of stomach cancer. The narrow CI, excluding 1.0 , and the low $\mathrm{p}$ value provide evidence that this result is not due to chance. A major finding here is that the summary relative risk for stomach cancer was elevated in those studies in which $\mathrm{Cr}(\mathrm{VI})$-associated lung cancer relative risks were also elevated, both in the analysis of all job categories combined (summary relative risk $=1.41 ; 1.18$ to $1.69 ; \mathrm{p}<0.001$ ) and in the analysis of chromium production and plating studies (summary relative risk $=1.36 ; 1.01$ to $1.81 ; \mathrm{p}=0.04)$. Since $\mathrm{Cr}(\mathrm{VI})$ exposures, in general, are likely to be higher in those studies where increases in lung cancer were found, the presence of a positive lung cancer finding may be a valid surrogate for high $\mathrm{Cr}(\mathrm{VI})$ exposure. As such, these latter findings provide additional evidence that the positive findings seen in this meta-analysis are due to $\mathrm{Cr}(\mathrm{VI})$.

Statistically significant heterogeneity was seen in the meta-analysis of all studies combined $\left(\chi^{2}=139.6, p<0.001\right)$, and the CIs of several studies did not include the summary relative risk. However, we did not see statistically significant heterogeneity in most other analyses performed, including the analyses of studies with elevated lung cancer risks $\left(\chi^{2}=22.6, p=0.31\right)$. In observational epidemiology, study designs, populations, methods of assessing exposure and outcome, and statistical analyses are rarely, if ever, the same. As such, some variation across study results is expected. The fact that statistical heterogeneity 
Table 1 Results of the meta-analysis of $\mathrm{Cr}(\mathrm{VI})$ exposure and stomach cancer

\begin{tabular}{|c|c|c|c|c|c|c|c|c|c|c|c|c|c|}
\hline & \multirow{2}{*}{$\begin{array}{l}\text { No. of } \\
\text { cases }\end{array}$} & \multirow{2}{*}{$\begin{array}{l}\text { No. of } \\
\text { results* }\end{array}$} & \multicolumn{3}{|c|}{ Fixed effects model } & \multicolumn{2}{|c|}{$\begin{array}{l}\text { Shore } \\
\text { adjusted CI }\end{array}$} & \multicolumn{3}{|c|}{ Random effects model } & \multicolumn{3}{|c|}{ Heterogeneity } \\
\hline & & & RRs & $\mathrm{Cl}_{\mathrm{L}}$ & $\mathrm{Cl}_{\mathrm{u}}$ & $\mathrm{Cl}_{\mathrm{L}}$ & $\mathrm{Cl}_{\mathrm{U}}$ & RRs & $\mathrm{Cl}_{\mathrm{L}}$ & $\mathrm{Cl}_{\mathrm{U}}$ & $\chi^{2}$ & $\mathrm{p}$ Value & $I^{2}(\%)$ \\
\hline All studies & 1399 & 74 & 1.27 & 1.20 & 1.35 & 1.18 & 1.38 & 1.28 & 1.16 & 1.41 & 139.6 & $<0.001$ & 47.7 \\
\hline \multicolumn{14}{|l|}{ Job type } \\
\hline Production or plating & 113 & 18 & 1.25 & 1.02 & 1.53 & 0.97 & 1.60 & 1.25 & 0.95 & 1.65 & 25.9 & 0.08 & 34.4 \\
\hline Cement work & 903 & 23 & 1.29 & 1.20 & 1.38 & 1.17 & 1.42 & 1.37 & 1.21 & 1.54 & 42.7 & 0.005 & 48.4 \\
\hline Leather work & 237 & 17 & 1.46 & 1.27 & 1.67 & 1.23 & 1.72 & 1.33 & 1.08 & 1.64 & 23.6 & 0.10 & 32.1 \\
\hline Welding & 31 & 4 & 1.06 & 0.72 & 1.55 & 0.72 & 1.56 & 1.08 & 0.72 & 1.56 & 3.0 & 0.39 & 0.8 \\
\hline All other & 115 & 12 & 0.96 & 0.79 & 1.17 & 0.69 & 1.33 & 1.12 & 0.78 & 1.60 & 31.7 & $<0.001$ & 65.3 \\
\hline \multicolumn{14}{|l|}{ Study design } \\
\hline Case-control & 130 & 11 & 1.55 & 1.16 & 2.07 & NA & NA & NA & NA & NA & 8.2 & 0.61 & NA \\
\hline Cohort & 1269 & 63 & 1.26 & 1.19 & 1.34 & 1.16 & 1.37 & 1.25 & 1.13 & 1.39 & 129.6 & $<0.001$ & 52.2 \\
\hline PMR studies & 353 & 10 & 1.60 & 1.43 & 1.78 & 1.43 & 1.78 & 1.60 & 1.43 & 1.79 & 9.3 & 0.41 & 2.9 \\
\hline SMR studies & 293 & 32 & 1.14 & 1.00 & 1.29 & 0.95 & 1.36 & 1.17 & 0.96 & 1.43 & 61.5 & $<0.001$ & 49.6 \\
\hline Other & 623 & 21 & 1.16 & 1.07 & 1.26 & 1.04 & 1.29 & 1.17 & 1.03 & 1.34 & 33.6 & 0.03 & 40.4 \\
\hline \multicolumn{14}{|l|}{ Incidence vs mortality } \\
\hline Incidence studies & 738 & 30 & 1.17 & 1.09 & 1.27 & 1.07 & 1.29 & 1.21 & 1.07 & 1.36 & 41.1 & 0.07 & 29.4 \\
\hline Mortality studies & 661 & 44 & 1.39 & 1.28 & 1.51 & 1.24 & 1.57 & 1.32 & 1.14 & 1.53 & 89.8 & $<0.001$ & 52.1 \\
\hline \multicolumn{14}{|l|}{ Gender } \\
\hline Males only & 1258 & 59 & 1.30 & 1.22 & 1.38 & 1.20 & 1.41 & 1.33 & 1.19 & 1.47 & 112.8 & $<0.001$ & 48.6 \\
\hline Females only & 23 & 6 & 1.08 & 0.72 & 1.63 & 0.65 & 1.81 & 1.14 & 0.61 & 2.11 & 8.0 & 0.16 & 37.4 \\
\hline \multicolumn{14}{|l|}{ Lung cancer $R R \geq 1.5$} \\
\hline All studies & 170 & 21 & 1.41 & 1.19 & 1.67 & 1.18 & 1.69 & 1.41 & 1.16 & 1.71 & 22.6 & 0.31 & 11.4 \\
\hline Production or plating & 78 & 13 & 1.36 & 1.06 & 1.73 & 1.01 & 1.81 & 1.31 & 0.96 & 1.80 & 16.9 & 0.15 & 29.0 \\
\hline \multicolumn{14}{|l|}{ Country, region } \\
\hline Europe & 859 & 48 & 1.16 & 1.08 & 1.25 & 1.06 & 1.27 & 1.20 & 1.06 & 1.35 & 78.2 & 0.003 & 39.9 \\
\hline North America & 419 & 16 & 1.50 & 1.36 & 1.66 & 1.31 & 1.72 & 1.47 & 1.24 & 1.75 & 27.9 & 0.02 & 46.3 \\
\hline Asia & 121 & 10 & 1.34 & 1.10 & 1.62 & 1.03 & 1.74 & 1.31 & 0.94 & 1.81 & 16.7 & 0.05 & 46.1 \\
\hline
\end{tabular}

*Some publications provided two or more results that met the inclusion criteria but did not involve overlapping populations (eg, separate results for males and females).

$\mathrm{Cl}_{\mathrm{L}}$, lower $95 \% \mathrm{Cl}_{;} \mathrm{Cl}_{\mathrm{U}}$, upper $95 \% \mathrm{Cl}_{;} \mathrm{I}^{2}$, the percentage of total variation across studies due to heterogeneity rather than chance; NA, not applicable (Shore adjusted $\mathrm{Cl}$ (applied to the fixed effects RR) and the random effects model are only used when the $\chi^{2}$ heterogeneity statistic is greater than the number of individual study results minus one); PMR, proportionate mortality ratio; RR, relative risk estimate; RRs, summary relative risk; SMR, standardised mortality ratio; $\chi^{2}, \chi^{2}$ heterogeneity statistic.

was not present in most of the subgroup analyses we performed highlights the overall consistency in many of these results. This consistency is supported by the fact that the large majority of individual $\mathrm{RR}$ estimates are $>1.0$. For example, in the analysis of all studies combined, 52 of $74 \mathrm{RR}$ estimates are $>1.0$. The probability that this would occur by chance alone is 0.0002 .

In this meta-analysis, as in almost all meta-analyses of epidemiological data, studies using different exposure metrics (eg, average exposure, exposure duration) were combined. The use of different metrics can potentially affect summary relative risks, but the likely direction is towards the null, not towards a false positive result. The reason for this is that if $\mathrm{Cr}(\mathrm{VI})$ is truly associated with stomach cancer, some metrics are likely to be more strongly associated with stomach cancer than others, and including less relevant metrics would dilute summary relative risks towards 1.0. If every study had reported data on the same single metric that was most strongly associated with stomach cancer, it is likely that the true summary relative risks would be even higher than those reported here. A similar effect could have resulted from our including studies with different levels of $\mathrm{Cr}$ (VI) exposure or different forms of $\mathrm{Cr}(\mathrm{VI})$. That is, if a true association exists, the inclusion of studies in which $\mathrm{Cr}(\mathrm{VI})$ exposures were relatively low would most likely bias results towards a summary relative risk of 1.0 , not towards a false association. Previous research suggests that the absorption fraction is higher for soluble chromium compounds than for insoluble forms. ${ }^{15}$
Few of the studies used in this meta-analysis provided details on $\mathrm{Cr}(\mathrm{VI})$ solubility. If less soluble forms are less carcinogenic, including studies involving these less soluble forms would dilute any associations due to soluble $\mathrm{Cr}(\mathrm{VI})$ to the null. It is most likely that all studies had at least some errors in assessing exposure. However, since they all assessed exposure using the same methods in people with and without cancer, this misclassification was most likely non-differential and also most likely biased findings towards the null.

Another factor that can potentially impact results is confounding. Most studies controlled for age and sex, but few adjusted for other factors (see online supplementalary table S1). The known risk factors for stomach cancer include older age; male sex; chronic gastritis and polyps; Helicobacter pylori infection, certain genetic abnormalities; lifestyle factors such as smoking, alcohol and diet (low fruit and vegetable intake or high intake of salted, smoked or nitrate-preserved foods); and coal mining, nickel refining, rubber and timber processing, and possibly exposure to asbestos. ${ }^{16}$ Importantly, confounding factors must typically be associated with both $\mathrm{Cr}(\mathrm{VI})$ and stomach cancer, and these associations must be fairly strong to cause important confounding. ${ }^{17}$ Some factors are most likely too rare (eg, genetic disorders, family history) or not associated strongly enough with $\mathrm{Cr}(\mathrm{VI})$ exposure (eg, Helicobacter pylori, a major risk factor for stomach cancer) to cause important confounding. Some cement products contain asbestos. ${ }^{18}$ Although 
Costantini et al., 1989

Dab et al., 2011

Danielsen et al., 1996

Davies et al., 1991 - Bolton

Davies et al., 1991 - Eaglescliff

Davies et al., 1991 - Rutherglen

Deschamps et al., 1995

Edling et al., 1986

Franchini et al., 1983

Garabrant and Wegman, 1984 - females

Garabrant and Wegman, 1984 - males

Gonzales et al., 1991 - bricklayer

Gonzales et al., 1991 - leather

Hara et al., 2010

Hayes et al., 1989

Horiguchi et al., 1990

Huvinen and Pukkala, 2013

Jakobsson et al., 1993

Jakobsson et al., 1997

Jarvholm et al., 1982

Kano et al., 1993

Kneller et al., 1990 - leather products

Kneller et al., 1990 - tanners

Koh et al., 2013

Korallus et al., 1993 - Leverkusen

Korallus et al., 1993 - Uerdingen

Krstev et al., 2005 - females

Krstev et al., 2005 - males

Langård et al., 1990

Lipworth et al., 2011

Mallin et al., 1989

McDowall, 1984 - packing

McDowall, 1984 - labor

McDowall, 1984 - maintenance

Mikoczy and Hagmar, 2005

Minder and Beer-Porizek, 1992

Montanaro et al., 1997

Moulin et al., 1990

Moulin et al., 1993a

Moulin et al., 1993b

Moulin et al., 1995 - plant 1

Moulin et al., 1995 - plant 2

Parent et al., 1998

Pippard et al., 1985

Pukkala et al., 2009 - Nordic

Pukkala et al., 2009 - Denmark

Pukkala et al., 2009 - Finland

Pukkala et al., 2009 - Norway

Rafnsson et al., 1997

Robinson et al., 1995

Rosenman and Stanbury, 1996

Salg and Alterman, 2005 - nonwhite

Salg and Alterman, 2005 - white

Santibanez et al., 2012 - bricklayer masons

Santibanez et al., 2012 - leather

Satoh et al., 1981

Silverstein et al., 1981 - males

Simonato et al., 1991

Sjödahl et al., 2007

Smailyte et al., 2004

Sorahan et al., 1987 - females

Sorahan et al., 1987 - males

Sorahan and Harrington, 2000

Stern et al., 2001

Sweeney et al., 1985

Walrath et al., 1987 - females

Walrath et al., 1987 - males

Weiderpass et al., 2003

Xu et al., 1996 - cement

Xu et al.,1996 - plating

Overall (I-squared $=47.7 \%, p=0.000)$

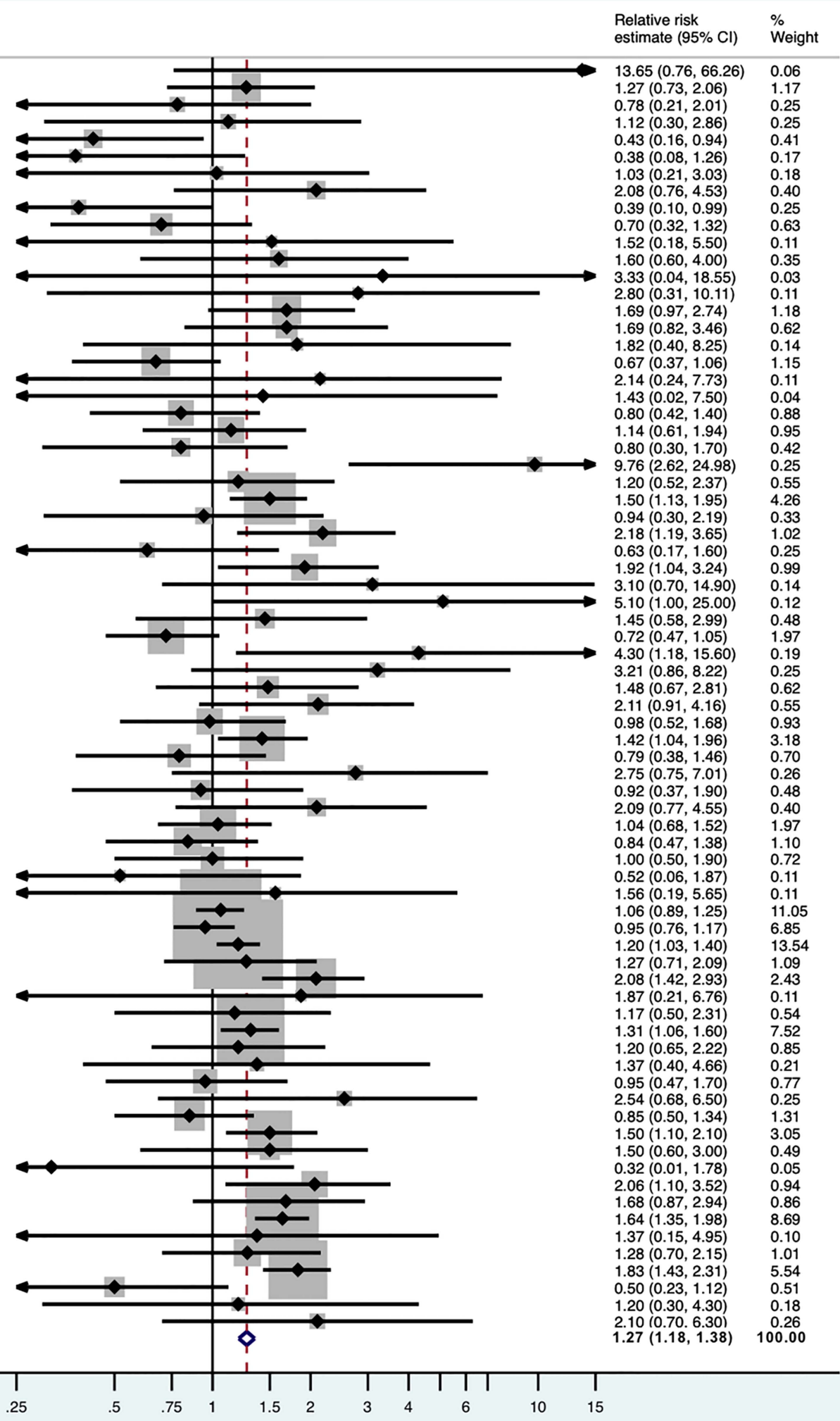

Relative risk estimate

Figure 1 Forest plot of studies included in the meta-analysis of $\operatorname{Cr}(\mathrm{VII})$ and stomach cancer: all studies combined.

this could have potentially confounded results in cement workers, we excluded studies specifically in asbestos cement workers. In addition, high asbestos exposures were not known to have occurred in the other occupational categories assessed and summary relative risk estimates in cement workers were similar to those in several other job categories. A few studies adjusted for smoking, diet or SES, but the impacts of these adjustments are inconsistent, with an increase in relative risk 
Study

ID $\begin{array}{ll}\text { Relative risk } & \% \\ \text { estimate }(95 \% \mathrm{Cl}) & \text { Weight }\end{array}$

Ahn et al., 2006

Davies et al., 1991 - Eaglescliff

Davies et al., 1991 - Rutherglen

Deschamps et al., 1995

Franchini et al., 1983

Hayes et al., 1989

Horiguchi et al., 1990

Korallus et al., 1993 - Leverkusen

Korallus et al., 1993 - Uerdingen

Langård et al., 1990

Minder and Beer-Porizek, 1992

Moulin et al., 1990

Rafnsson et al., 1997

Rosenman and Stanbury, 1996

Satoh et al., 1981

Silverstein et al., 1981 - males

Smailyte et al., 2004

Sorahan et al., 1987 - males

Sorahan and Harrington, 2000

Sweeney et al., 1985

Xu et al., 1996 - cement

Overall $(\mathrm{I}$-squared $=11.3 \%, p=0.311$ )

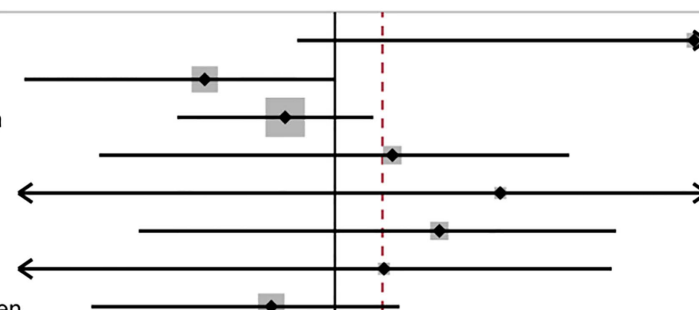

$13.65(0.76,66.26) \quad 0.57$

$0.39(0.10,0.99) \quad 2.25$

$0.70(0.32,1.32) \quad 5.62$

$1.52(0.18,5.50) \quad 0.98$

$3.33(0.04,18.55) \quad 0.31$

$2.14(0.24,7.73) \quad 0.95$

$1.43(0.02,7.50) \quad 0.33$

$0.63(0.17,1.60) \quad 2.27$

$1.92(1.04,3.24) \quad 8.84$

$1.45(0.58,2.99) \quad 4.26$

$1.42(1.04,1.96) \quad 28.43$

$2.75(0.75,7.01) \quad 2.29$

$1.27(0.71,2.09) \quad 9.79$

$1.87(0.21,6.76) \quad 0.95$

$0.95(0.47,1.70) \quad 6.91$

$2.54(0.68,6.50) \quad 2.24$

$1.50(0.60,3.00) \quad 4.41$

$2.06(1.10,3.52) \quad 8.37$

$1.68(0.87,2.94) \quad 7.70$

$1.37(0.15,4.95) \quad 0.93$

$1.20(0.30,4.30) \quad 1.61$

$1.41(1.18,1.69) \quad 100.00$

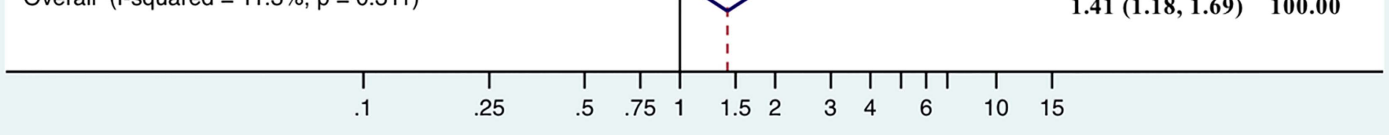

Relative risk estimate

Figure 2 Forest plot of studies included in the meta-analysis of $\mathrm{Cr}(\mathrm{VI})$ and stomach cancer: only studies with lung cancer relative risk estimates $\geq 1.5$.

estimates in some studies but a decrease in others. Axelson has shown that confounding by smoking may cause relative risks as high as 1.5 for lung cancer in occupational studies. ${ }^{17}$ However, smoking-associated relative risks for stomach cancer are much lower than those for lung cancer, so the impact of smoking as a confounder is likely to be much less in studies of stomach cancer than in studies of lung cancer. Using the Axelson methods, and data on smoking-stomach cancer relative risks (about 1.5), ${ }^{19}$ we estimated that confounding by smoking is unlikely to cause a relative risk $>1.1$ in occupational studies of stomach cancer.

The higher summary relative risks we identified for studies with positive lung cancer findings may indicate higher $\mathrm{Cr}(\mathrm{VI})$ exposure or it may indicate greater confounding by smoking. However, in a meta-analysis of those studies with lung cancer relative risk estimates $\geq 1.5$ that provided data on non-malignant
Figure 3 Funnel plot of studies included in the meta-analysis of $\mathrm{Cr}(\mathrm{VI})$ and stomach cancer: all studies combined.

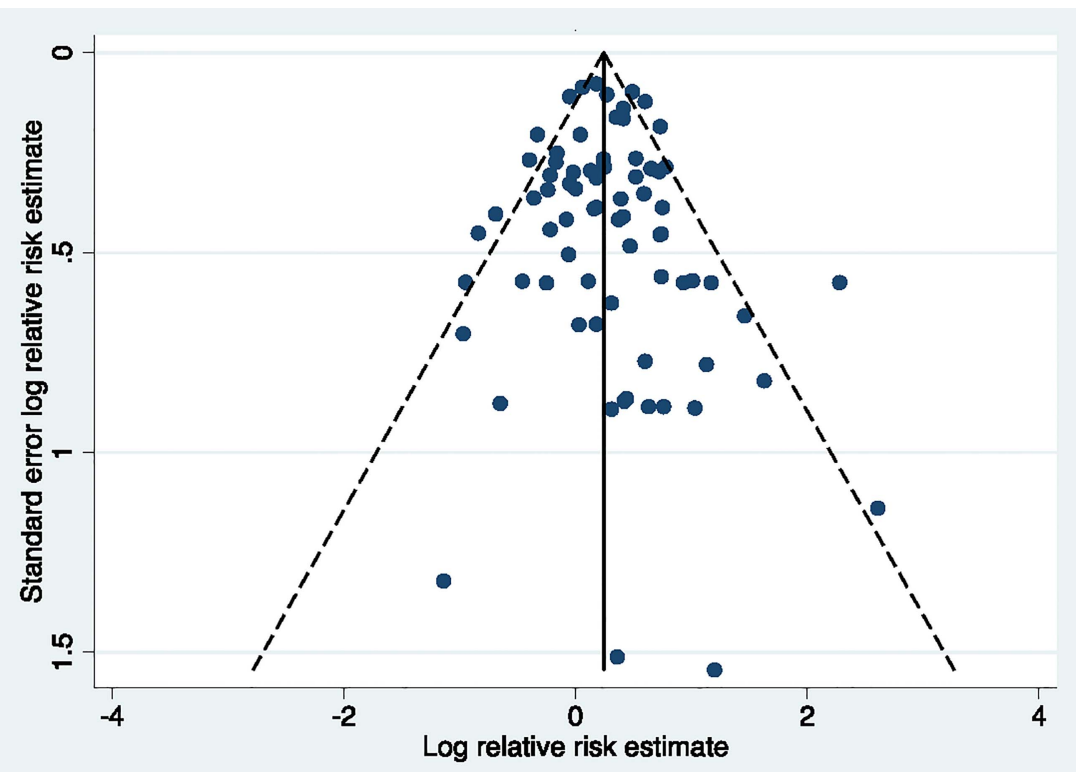


respiratory disease (which is also caused by smoking), the summary RR for non-malignant respiratory disease was not elevated $(\mathrm{RR}=1.00 ; 95 \% \mathrm{CI} 0.71$ to $1.40 ; \mathrm{n}=9$; median relative risk estimate $=0.91$ ), providing evidence that smoking did not confound our results.

Other potential biases include the healthy worker effect and biases related to the inclusion of case-control studies (eg, recall bias or biased selection of controls). Although the summary relative risk for case-control studies was higher than that for cohort studies, the difference between these two was not statistically significant $(p=0.18)$. The healthy worker effect would primarily affect studies comparing exposed workers to the general population (eg, SMRs) and this effect would most likely bias SMRs downwards. Although the extent of this bias here is unknown, evidence of the healthy worker effect has been reported for several different cancer types and in a number of different occupational settings. ${ }^{20-22}$

In this meta-analysis, neither visual inspection of the funnel plot nor Egger's or Begg's test showed evidence of publication bias, although the funnel plots are open to subjective interpretation, and Egger's and Begg's tests can be affected by factors other than this bias. Overall, while we did not see clear evidence of this bias, it is potentially an issue in any meta-analysis.

Two previous meta-analyses of $\mathrm{Cr}(\mathrm{VI})$ and stomach cancer have been published. In Gatto et al, ${ }^{23}$ the summary relative risk involving 29 studies was 1.09 (95\% CI 0.93 to 1.28 ). Similar to our meta-analysis, the Gatto et al meta-analysis included studies of chromium production, cement and leather workers (see online supplementalary table S3), but the individual study results are presented only in figure form, making direct comparisons with our meta-analysis difficult. One clear difference is our inclusion of many more results (74 vs 29), particularly from cement and leather workers, but also from studies of stainless steel and chromium plating workers. The summary relative risk using the individual RR estimates we abstracted for the 29 studies used by Gallo et al was somewhat lower than our meta-analysis of all 74 studies $(1.22 ; 95 \%$ CI 1.05 to 1.41 vs $1.27 ; 95 \%$ CI 1.18 to 1.38 ). Another difference may have been our use of RR estimates from subgroups that are more likely to be highly exposed (eg, exposure duration $\geq 10$ years), although direct comparisons are difficult for the reason given above. We also excluded five studies used by Gatto et al because they were unpublished, involved painters or foundry workers with uncertain exposure, ${ }^{24} 25$ or overlapped with the already included studies. ${ }^{26}{ }^{27}$ However, adding these five excluded studies to our meta-analysis of all studies caused little change $(1.27 ; 95 \%$ CI 1.18 to 1.37 ) since most of these studies only received a small amount of the total weighting. In a meta-analysis by Cole and Rodu, the authors reported that the summary relative risk between $\mathrm{Cr}(\mathrm{VI})$ and stomach cancer was lower in studies that adjusted for SES than in studies that did not adjust for this variable ( $\mathrm{RR}=0.8295 \%$ CI 0.69 to 0.96 vs $\mathrm{RR}=1.37 ; 95 \% \mathrm{CI}$ 1.23 to 1.53 ), and concluded that SES was responsible for any apparent association seen between chromium exposure and stomach cancer. ${ }^{28}$ However, one of the authors' criteria for these analyses was that studies "that were negative or essentially negative with respect to chrome exposure were included with the papers that were controlled [for SES]." In our evaluation of the studies used by these authors in their SES-controlled analysis, we were unable to find any mention of adjustments for SES (or any related variable) in 13 of the 14 studies (93\%) included. Thus, the subgroup analysis titled 'SES-controlled' appears to be a misnomer, and instead reflects their criterion of studies that were 'negative or essentially negative with respect to chrome exposure.'

A variety of data support the biological plausibility of our results. $\mathrm{Cr}(\mathrm{VI})$ is a well-documented human lung carcinogen, and there is abundant evidence that airborne $\mathrm{Cr}(\mathrm{VI})$ is systemically absorbed. For example, studies in a variety of occupational settings have shown that $\mathrm{Cr}(\mathrm{VI})$ exposed workers have elevated blood or urine chromium levels compared to unexposed controls. ${ }^{29} 30$ These data show that airborne $\mathrm{Cr}(\mathrm{VI})$ not only reaches the lungs, but that at least some of it is also internally absorbed and therefore most likely distributed to other organs. This systemic absorption may occur directly through the lungs, or particulates containing $\mathrm{Cr}(\mathrm{VI})$ that settle in the trachea and bronchi may be cleared by mucociliary action and then swallowed. ${ }^{31}$ This swallowed $\mathrm{Cr}(\mathrm{VI})$ would come into direct contact with the stomach mucosa. Once in the stomach, ingested $\mathrm{Cr}(\mathrm{VI})$ is reduced by the acidic environment of the stomach to $\mathrm{Cr}(\mathrm{III})$, which is poorly absorbed. However, this reduction may not be complete, and most studies suggest that at least some ingested $\mathrm{Cr}(\mathrm{VI})$ escapes gastric reduction and is absorbed. ${ }^{32}$ In studies in rodents, administration of $\mathrm{Cr}(\mathrm{VI})$ in drinking water has resulted in statistically significant increases in benign and malignant stomach tumours (combined), ${ }^{31} 33$ papillomas or carcinomas (combined) of the oral cavity, and adenomas or carcinomas (combined) of the small intestine. ${ }^{34}$ In humans, Beaumont et $a l^{35}$ reported a RR of 1.82 (95\% CI 1.11 to 2.91) for stomach cancer mortality in an area where $\mathrm{Cr}(\mathrm{VI})$ pollution from a ferrochromium factory caused widespread $\mathrm{Cr}(\mathrm{VI})$ contamination of nearby drinking water sources, although issues of dose-response and other potential biases have been debated. ${ }^{36}{ }^{37}$ In an ecological study in a province in Greece with Cr-contaminated water, SMRs were elevated for liver $(\mathrm{SMR}=11.0 ; \quad 95 \% \quad \mathrm{CI} \quad 4.05$ to 24.0$)$ and lung cancer $(\mathrm{SMR}=1.45 ; 95 \%$ CI 1.00 to 2.03$) .{ }^{38}$ The SMR for stomach cancer was above 1.0 but was not statistically significant $(\mathrm{SMR}=1.21 ; 95 \%$ CI 0.44 to 2.63$)$.

The exact mechanisms by which $\mathrm{Cr}(\mathrm{VI})$ causes cancer are unknown, but evidence for several possible mechanisms exists. These include indirect and direct effects on DNA, epigenetic effects, gene regulation effects and direct cytotoxicity. $\mathrm{Cr}(\mathrm{VI})$ readily enters cells via active transport through anion channels and intracellular reduction follows, producing reactive intermediate $\mathrm{Cr}$ valences, $\mathrm{Cr}(\mathrm{V})$ and $\mathrm{Cr}(\mathrm{IV})$ and ultimately $\mathrm{Cr}(\mathrm{III})$, which is DNA-reactive. Reactive oxygen species, oxygen radicals and other reactive molecules generated during this reduction process are postulated to have genotoxic effects as well. ${ }^{39-46}$ In vitro studies have revealed that $\mathrm{Cr}(\mathrm{VI})$-induced mutations can be generated through different types of DNA damage such as interstrand crosslinks, DNA-protein crosslinks and DNA adducts, as well as single-strand and double-strand DNA breaks. 414748 Studies of $\mathrm{Cr}(\mathrm{VI})$-exposed tannery workers show evidence of genotoxic effects including chromosomal aberration, micronuclei formation, DNA breaks and higher levels of DNA damage in lymphocytes as determined by a comet assay. ${ }^{49-52}$ In a study of chrome plating workers, chromium-induced DNA damage as measured by three comet assay components was significantly increased in exposed workers. ${ }^{29}$ As a whole, these studies, along with the positive animal bioassays discussed above, ${ }^{34}$ all provide biological plausibility for the findings of this meta-analysis.

\section{CONCLUSIONS}

The results of this meta-analysis suggest that $\mathrm{Cr}(\mathrm{VI})$ exposure is associated with increased risks of stomach cancer. An important feature of this study is that summary relative risks were elevated 
in a number of different occupational settings and in the subgroup of studies in which lung cancer risks were also elevated. As with almost all meta-analyses, confounding and publication bias cannot be entirely ruled out. Few studies adjusted for some of the known risk factors of stomach cancer, including smoking, although an analysis of the potential magnitude of confounding from smoking suggests that this was unlikely to have caused the associations we observed. The exact relevance of our findings to $\mathrm{Cr}(\mathrm{VI})$ in drinking water is unknown. Differences in reduction and absorption patterns across the different routes of exposure could potentially impact toxicity. For example, the acidic environment of the stomach converts some ingested $\mathrm{Cr}(\mathrm{VI})$ to the poorly absorbed $\mathrm{Cr}(\mathrm{III})$, although several studies have shown that this process is not complete and some ingested $\mathrm{Cr}(\mathrm{VI})$ is absorbed. ${ }^{53}{ }^{54}$ Another difference is that drinking water exposures are generally much lower than occupational exposures, and this meta-analysis cannot be used to define exact doseresponse relationships or low exposure risks. However, owing to the difficulties associated with studying lower exposures in human populations (a greater probability of bias, confounding and insufficient power), ${ }^{6} 3755$ chemical risk assessments and regulatory standards are frequently based on higher exposure occupational studies like the ones used here. ${ }^{56}$ Another consideration is that drinking water exposures may cause greater toxicity because they can take place over the long term (eg, lifetime) and are more likely to occur at particularly susceptible life stages (eg, in fetuses, children and pregnant women) than exposures occurring at work. Thus, despite the different route and magnitude of exposure, our findings could have some relevance to efforts to regulate $\mathrm{Cr}(\mathrm{VI})$ in water in that they provide evidence that $\mathrm{Cr}(\mathrm{VI})$ is a cause of cancer in the human gastrointestinal tract and support the animal and limited human data linking ingested $\mathrm{Cr}(\mathrm{VI})$ to stomach cancer. US EPA and some states are considering regulating $\mathrm{Cr}(\mathrm{VI})$ in drinking water based on its potential carcinogenicity in the gastrointestinal tract, and California has recently established the first drinking water standard for $\mathrm{Cr}(\mathrm{VI})$ in the USA. The results of this study support such efforts.

Contributors CS, JJB, RW and GVA conceptualised the project and designed the overall study methods; CS and RW performed the literature searches and the statistical analyses; CS, JJB, RW, SJP and GVA assisted in the interpretation of results and writing.

Disclaimer The views expressed are those of the authors and do not necessarily represent those of the Office of Environmental Health Hazard Assessment, the California Environmental Protection Agency or the state of California.

\section{Competing interests None.}

Provenance and peer review Not commissioned; externally peer reviewed.

\section{REFERENCES}

1 Straif $\mathrm{K}$, Benbrahim-Tallaa L, Baan $\mathrm{R}$, et al. A review of human carcinogens-part C: metals, arsenic, dusts, and fibres. Lancet Oncol 2009;10:453-4.

2 Sutton R. Chromium-6 in U.S. Tap Water. Washington, DC: Environmental Working Group, 2010. http://www.ewg.org/chromium6-in-tap-water (accessed 23 Jul 2012).

3 Breslow NE, Day NE. Statistical methods in cancer research. Vol. 2. The design and analysis of cohort studies. Lyon: International Agency for Research on Cancer, 1987.

4 Lubin JH, Caporaso N, Wichmann HE, et al. Cigarette smoking and lung cancer: modeling effect modification of total exposure and intensity. Epidemiology 2007; 18:639-48

5 Lubin JH, Moore LE, Fraumeni JF Jr, et al. Respiratory cancer and inhaled inorganic arsenic in copper smelters workers: a linear relationship with cumulative exposure that increases with concentration. Environ Health Perspect 2008;116:1661-5.

6 Hill AB. The environment and disease: association or causation? Proc $R$ Soc Med 1965;58:295-300.

7 Rothman K, Greenland S. Causation and causal inference. In: Rothman K, Greenland S. eds. Modern epidemiology. 2nd edn. Philadelphia: Lippincott Raven, 1998:7-28.
8 DerSimonian R, Laird N. Meta-analysis in clinical trials. Control Clin Trials 1986:8:177-88.

9 Greenland S. Quantitative methods in the review of epidemiologic literature. Epidemiol Rev 1987:9:1-30.

10 Petitti D. Meta-analysis, decision analysis, and cost effective analysis: methods for quantitative synthesis in medicine. New York: Oxford University Press, 1994.

11 Poole C, Greenland S. Random-effects meta-analyses are not always conservative. Am J Epidemiol 1999:150:469-75.

12 Shore R, Gardner M, Pannett B. Ethylene oxide: an assessment of the epidemiological evidence on carcinogenicity. Br J Ind Med 1993;50:971-97.

13 Begg CB, Mazumdar M. Operating characteristics of a rank correlation test for publication bias. Biometrics 1994;50:1088-101.

14 Egger M, Davey Smith G, Schneider M, et al. Bias in meta-analysis detected by a simple, graphical test. BMJ 1997;315:629-34.

15 Agency for Toxic Substances and Disease Registry (ATSDR). Toxicological profile for Chromium. Atlanta, GA: U.S. Department of Health and Human Services, Public Health Service, 2012.

16 Brenner $\mathrm{H}$, Rothenbacher $\mathrm{D}$, Arndt V. Epidemiology of stomach cancer. Methods Mol Biol 2009;472:467-77.

17 Axelson 0. Aspects on confounding in occupational health epidemiology. Scand J Work Environ Health 1978;4:98-102.

18 Williams PR, Phelka AD, Paustenbach DJ. A review of historical exposures to asbestos among skilled craftsmen (1940-2006). J Toxicol Environ Health B Crit Rev 2007;10:319-77.

19 Ladeiras-Lopes R, Pereira AK, Nogueira A, et al. Smoking and gastric cancer: systematic review and meta-analysis of cohort studies. Cancer Causes Control 2008;19:689-701.

20 Kirkeleit J, Riise T, Bjorge $\mathrm{T}$, et al. The healthy worker effect in cancer incidence studies. Am J Epidemiol 2013;177:1218-24.

21 Pukkala E, Martinsen Jl, Lynge E, et al. Occupation and cancer-follow-up of 15 million people in five Nordic countries. Acta Oncol 2009;48:646-790.

22 Steinmaus $\mathrm{C}$, Smith $\mathrm{AH}$, Jones RM, et al. Meta-analysis of benzene exposure and non-Hodgkin lymphoma: biases could mask an important association. Occup Environ Med 2008;65:371-8.

23 Gatto NM, Kelsh MA, Mai DH, et al. Occupational exposure to hexavalent chromium and cancers of the gastrointestinal tract: a meta-analysis. Cancer Epidemiol 2010;34:388-99.

24 Guberan E, Usel M, Raymond L, et al. Disability, mortality, and incidence of cancer among Geneva painters and electricians: a historical prospective study. $\mathrm{Br} J$ Ind Med 1989;46:16-23.

25 Sorahan T, Faux AM, Cooke MA. Mortality among a cohort of United Kingdom steel foundry workers with special reference to cancers of the stomach and lung, 1946-90. Occup Environ Med 1994;51:316-22.

26 Costantini AS, Paci E, Miligi L, et al. Cancer mortality among workers in the Tuscan tanning industry. Br J Ind Med 1989;46:384-8.

27 laia TE, Bartoli D, Calzoni P, et al. A cohort mortality study of leather tanners in Tuscany, Italy. Am J Ind Med 2006;49:452-9.

28 Cole P, Rodu B. Epidemiologic studies of chrome and cancer mortality: a series of meta-analyses. Regul Toxicol Pharmacol 2005;43:225-31.

29 Danadevi K, Rozati R, Banu BS, et al. Genotoxic evaluation of welders occupationally exposed to chromium and nickel using the Comet and micronucleus assays. Mutagenesis 2004;19:35-41.

30 Gambelunghe A, Piccinini R, Ambrogi $\mathrm{M}$, et al. Primary DNA damage in chrome-plating workers. Toxicology 2003;188:187-95.

31 Sedman RM, Beaumont J, McDonald TA, et al. Review of the evidence regarding the carcinogenicity of hexavalent chromium in drinking water. J Environ Sci Health C Environ Carcinog Ecotoxicol Rev 2006;24:155-82.

32 Donaldson RM Jr, Barreras RF. Intestinal absorption of trace quantities of chromium. J Lab Clin Med. 1966;68:484-93.

33 Borneff J, Engelhardt K, Griem W, et al. [Carcinogens in water and soil. XXII. Experiment with 3,4-benzopyrene and potassium chromate in mice drink]. Arch Hyg Bakteriol 1968;152:45-53.

34 NTP. Technical Report on the Toxicology and Carcinogenesis Studies of Sodium Dichromate Dihydrate in F344/N Rats and B6C3F1 Mice. NTP TR 546. NIH Publication No. 07-5887. Research Triangle Park, North Carolina: National Toxicology Program, 2008. http://ntp.niehs.nih.gov/ntp/htdocs/LT_rpts/tr546.pdf (accessed 10 Mar 2011).

35 Beaumont JJ, Sedman RM, Reynolds SD, et al. Cancer mortality in a Chinese population exposed to hexavalent chromium in drinking water. Epidemiology 2008;19:12-23.

36 Paustenbach DJ. On the chromium reanalysis. Epidemiology 2009;20:625-6; author reply $6-7$.

37 Smith AH. Hexavalent chromium, yellow water, and cancer: a convoluted saga. Epidemiology 2008;19:24-6.

38 Linos A, Petralias A, Christophi CA, et al. Oral ingestion of hexavalent chromium through drinking water and cancer mortality in an industrial area of Greece-an ecological study. Environ Health 2011;10:50.

39 Benova D, Hadjidekova V, Hristova R, et al. Cytogenetic effects of hexavalent chromium in Bulgarian chromium platers. Mutat Res 2002;514:29-38. 
40 Kasprzak KS. Possible role of oxidative damage in metal-induced carcinogenesis. Cancer Invest 1995:13:411-30.

41 O'Brien TJ, Ceryak S, Patierno SR. Complexities of chromium carcinogenesis: role of cellular response, repair and recovery mechanisms. Mutat Res 2003;533:3-36.

42 Shi X, Chiu A, Chen CT, et al. Reduction of chromium(VI) and its relationship to carcinogenesis. J Toxicol Environ Health B Crit Rev 1999;2:87-104.

43 Sugden KD, Burris RB, Rogers SJ. An oxygen dependence in chromium mutagenesis. Mutat Res 1990;244:239-44.

44 Sugiyama M. Role of physiological antioxidants in chromium(VI)-induced cellular injury. Free Radic Biol Med 1992;12:397-407.

45 Vaglenov A, Nosko M, Georgieva R, et al. Genotoxicity and radioresistance in electroplating workers exposed to chromium. Mutat Res 1999:446:23-34.

46 Witt KL, Stout MD, Herbert RA, et al. Mechanistic insights from the NTP studies of chromium. Toxicol Pathol 2013;41:326-42.

47 Jomova K, Valko M. Advances in metal-induced oxidative stress and human disease. Toxicology 2011;283:65-87.

48 McCarroll N, Keshava N, Chen J, et al. An evaluation of the mode of action framework for mutagenic carcinogens case study II: chromium (VI). Environ Mol Mutagen 2010;51:89-111.

49 Balachandar V, Arun M, Mohana Devi S, et al. Evaluation of the genetic alterations in direct and indirect exposures of hexavalent chromium $[\mathrm{Cr}(\mathrm{VI})]$ in leather tanning industry workers North Arcot District, South India. Int Arch Occup Environ Health 2010;83:791-801.

50 Medeiros MG, Rodrigues AS, Batoreu MC, et al. Elevated levels of DNA-protein crosslinks and micronuclei in peripheral lymphocytes of tannery workers exposed to trivalent chromium. Mutagenesis 2003;18:19-24.

51 Sbrana I, Caretto S, Lascialfari D, et al. Chromosomal monitoring of chromium-exposed workers. Mutat Res 1990;242:305-12.

52 Zhang $\mathrm{M}$, Chen $\mathrm{Z}$, Chen $\mathrm{Q}$, et al. Investigating DNA damage in tannery workers occupationally exposed to trivalent chromium using comet assay. Mutat Res 2008:654:45-51.

53 Finley BL, Kerger BD, Katona MW, et al. Human ingestion of chromium (VI) in drinking water: pharmacokinetics following repeated exposure. Toxicol Appl Pharmacol 1997;142:151-9.

54 Kerger BD, Paustenbach DJ, Corbett GE, et al. Absorption and elimination of trivalent and hexavalent chromium in humans following ingestion of a bolus dose in drinking water. Toxicol Appl Pharmacol 1996;141:145-58.

55 Gibb H, Haver C, Gaylor D, et al. Utility of recent studies to assess the National Research Council 2001 estimates of cancer risk from ingested arsenic. Environ Health Perspect 2011;119:284-90.

56 U.S. Environmental Protection Agency. Integrated Risk Information System. 2013. http://www.epa.gov/RIS/ (accessed 10 Jul 2013). 